\title{
Efficient Removal of Impulse Noise from Digital Images
}

\author{
Chhavi Sharma \\ Computer Science and engineering, ITM \\ University Gurgaon India
}

\begin{abstract}
Digital images can be corrupted by impulse noise. An effort has been made to remove impulse noise from the digital images. The impulse noise can be added to consumer based like television and digital cameras. The algorithm to remove impulse noise from digital images must be simple and remove noise efficiently and at the same time must also retain the details of an image.
\end{abstract}

\section{General Terms}

Pattern recognition, Impulse noise

\section{Keywords}

detection of impulse noise, image enhancement, impulse noise.

\section{INTRODUCTION}

The acquisition of digital images involves some impulse noise added at the time of acquisition. Impulse noise can be added at various stages such as at the time of image acquisition, image transmission, image recording. Impulse noise can be generated by various sources such as due to electronic appliances or atmospheric disturbances. So to improve the quality of images, removal or elimination of impulse noise is a very important step involved.

There are many impulse detection techniques available today which are mainly based on various techniques such as local signal statistics [1], fuzzy based techniques [2], weighted median [3][13], rank order thresholding methods [4] require prior training. An impulse detection which is based on rank order thresholding and soft switching impulse detector. A number of algorithms exists which are capable of eliminating impulse noise and at the same time details of the image are also being preserved such as median filter and its modification [5] has the capability of suppressing noise. There is a disadvantage involved in median filter approach that it tends to modify noise free pixels along with noisy pixels as this algorithm is implemented across the image in a uniform manner.

Median filter is a filtering technique [6][7][8]. While using median filter the finer details of a image are lost because it uniformly modifies all the pixels of an image. To eliminate the drawbacks of the median filter technique an approach of removing noise based on some decision is given in [23]. This paper has put forward a decision based algorithm signal adaptive median algorithm. The aim was to detect noise with accuracy, high PSNR value and also preserving the edges of the image for the finer details.

The paper that makes several other modification of median division are[19][20][21][22]. In decision based filtering classification plays an important role.

\author{
Neha Sahu \\ Computer Science and engineering ITM University \\ Gurgaon India
}

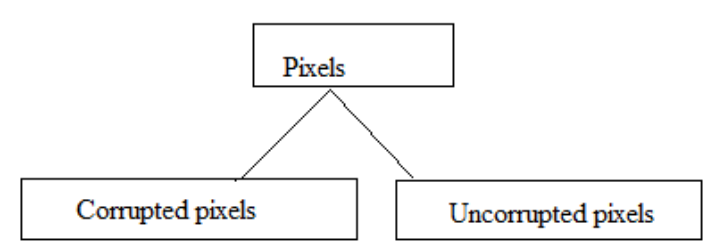

Fig. 1. In decision based filtering classification plays an important role

Classification of pixels into corrupted or uncorrupted pixels is based on decision rules. It needs defined decision measure for the representation of local property. The paper selectively applies the filtering operation on the corrupted pixels. The algorithm outperforms many other existing techniques.

Comparison of various filters is done in [9]. Noise can be removed from images by using filters. There are various filters available which can differ in performance. Different kind of noise such as Gaussian noise, salt and pepper noise, poison noise, speckle noise can be added to an image. It is very important to remove noise from images using filters. In [9] the performance of various filters is compared based on the PSNR value. PSNR is peak signal to noise ratio which can be used to compare original image with the image after the removal of noise. A higher PSNR value indicates that the image is less noisy $[10,11]$. Noise removal is a very important concept in image processing. Addition of noise in images leads to error at the time of taking decisions based on the images.

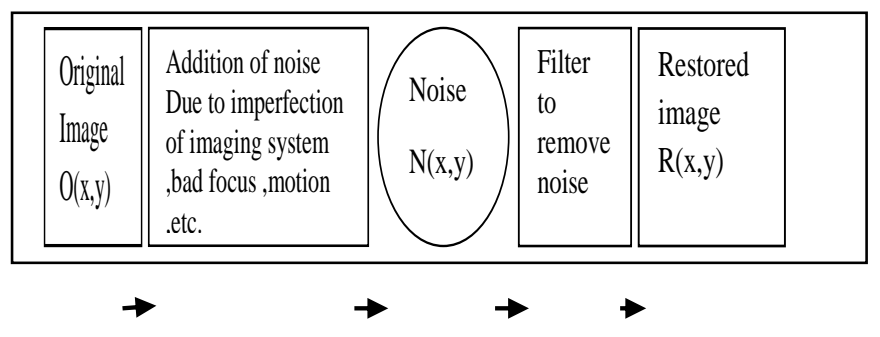

Fig. 2. Process of de-noising and restoration of an image.

To restore images by removing different kind of noises various filters are reviewed in [11]. Based on the review of [11] below tables are formulated.

Table 1. Showing advantages and drawbacks of various filters used to remove noise from an image.

\begin{tabular}{|c|c|}
\hline Filters & Advantages and Drawbacks \\
\hline Median filter & $\begin{array}{c}\text { Most popular, simple to } \\
\text { implement and efficient filter. } \\
\text { Causes blurring in the image. }\end{array}$ \\
\hline Adaptive median filter & Does not change pixel value. \\
\hline
\end{tabular}




\begin{tabular}{|c|c|}
\hline Mean filters & $\begin{array}{c}\text { Will not smear detect pixels } \\
\text { in high noise level. }\end{array}$ \\
\hline Good behaviour in presence \\
$\begin{array}{c}\text { Goor simpler structure } \\
\text { of signal dependent noises } \\
{[15]}\end{array}$ \\
\hline Adaptive wiener filter & $\begin{array}{c}\text { Known for blurring and } \\
\text { suppressing the noise [16]. }\end{array}$ \\
\hline & $\begin{array}{c}\text { Statistical approach to filter } \\
\text { out the noises } \\
\text { throughout the image because } \\
\text { in each region the } \\
\text { characteristics of an image are } \\
\text { not the same. } \\
\text { Reduces blurring of an image. } \\
\text { Produces edges of good } \\
\text { sharpness }\end{array}$ \\
\hline
\end{tabular}

Table 2. Showing specific features of different kinds of noise.

\begin{tabular}{|c|c|}
\hline Noise & Specific features \\
\hline Gaussian noise & $\begin{array}{c}\text { It can influence the values of } \\
\text { all the pixels. }\end{array}$ \\
\hline Salt and pepper noise & $\begin{array}{c}\text { Contains black and white } \\
\text { spots in an image. } \\
\text { Caused due to errors in data } \\
\text { transmission and image } \\
\text { sensor. }\end{array}$ \\
\hline Poisson noise & $\begin{array}{c}\text { Electronic noise caused by } \\
\text { the paucity of photons. }\end{array}$ \\
\hline Speckle noise & $\begin{array}{c}\text { It is a multiplicative noise } \\
\text { caused by coherent } \\
\text { processing of backscattered } \\
\text { signals from multiple } \\
\text { distributed objects. } \\
\text { Enriches the mean grey level } \\
\text { of a local area [17, 18]. }\end{array}$ \\
\hline
\end{tabular}

The filter which is most appropriate to remove the noise of varying density is shown below in the form of table.

Table 3. Showing appropriate filters for two different noise densities.

\begin{tabular}{|c|c|c|}
\hline Noise & Noise density & $\begin{array}{c}\text { Appropriate } \\
\text { Filter }\end{array}$ \\
\hline Speckle Noise & $\begin{array}{l}\text { Low Noise } \\
\text { Density }\end{array}$ & $\begin{array}{c}\text { Adaptive Wiener } \\
\text { Filter }\end{array}$ \\
\hline Speckle Noise & $\begin{array}{l}\text { High Noise } \\
\text { Density }\end{array}$ & Mean Filter \\
\hline Gaussian Noise & $\begin{array}{l}\text { Low Noise } \\
\text { Density }\end{array}$ & $\begin{array}{c}\text { Adaptive Wiener } \\
\text { Filter }\end{array}$ \\
\hline Gaussian Noise & $\begin{array}{c}\text { High Noise } \\
\text { Density }\end{array}$ & $\begin{array}{c}\text { Adaptive Wiener } \\
\text { Filter }\end{array}$ \\
\hline $\begin{array}{c}\text { Salt and Pepper } \\
\text { Noise }\end{array}$ & $\begin{array}{c}\text { Low Noise } \\
\text { Density }\end{array}$ & Adaptive Median \\
\hline $\begin{array}{l}\text { Salt and Pepper } \\
\text { Noise }\end{array}$ & $\begin{array}{l}\text { High Noise } \\
\text { Density }\end{array}$ & Adaptive Median \\
\hline Poison & $\begin{array}{l}\text { Low Noise } \\
\text { Density }\end{array}$ & $\begin{array}{c}\text { Adaptive Wiener } \\
\text { Filter }\end{array}$ \\
\hline Poison & $\begin{array}{l}\text { High Noise } \\
\text { Density }\end{array}$ & $\begin{array}{c}\text { Adaptive Wiener } \\
\text { Filter }\end{array}$ \\
\hline
\end{tabular}

According to table 3, in speckle noise if the noise density is low i.e. noise is between $10 \%-30 \%$ then Adaptive Wiener Filter works best. In high density speckle noise i.e. noise density between $40 \%-80 \%$ mean filter is considered to be the best filter for denoising images. Adaptive Wiener Filter gives the best performance for low density noise as well as high density noise for Gaussian noise. For low density noise and high density noise of Salt and Pepper, Adaptive Median is the best performer. For low density noise and high density noise in case of poison noise, Adaptive Wiener is the best performer.

\section{A NEW APPROACH TO REMOVE IMPULSE NOISE}

The noise considered in this paper is salt and paper impulse noise as shown in [12][1] [13]. In the case of salt and pepper noise there are only two possibilities each image pixels either has value 0 or 255 .

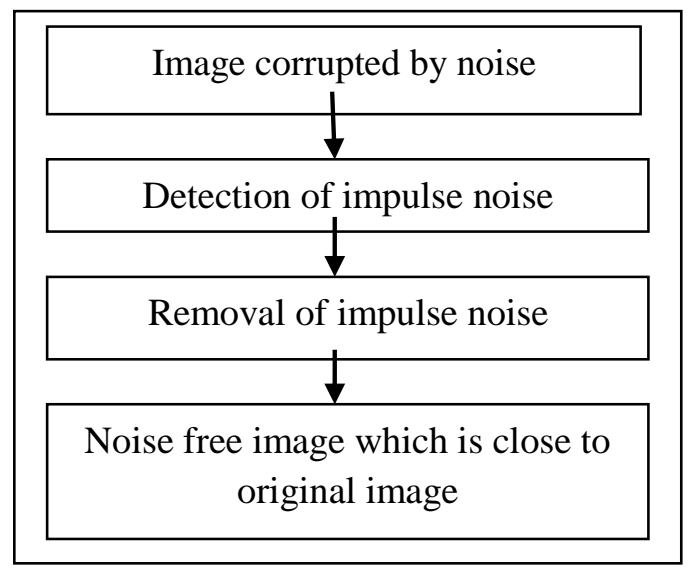

Fig. 3. Algorithm to remove impulse noise

\subsection{Detection of Impulse Noise using Fuzzy Based Approach}

The idea is to examine each pixel of the input image and to find out whether the pixel is corrupted by impulse noise or not .The detection of the impulse noise is making use of fuzzy based approach.

Let I be an input image. Let the size of image be $\mathrm{M} \times \mathrm{N}$. $\mathrm{X}$ i,j denotes the value of pixel at the position $i$ and $j$ respectively. In paper [13] it is clearly depicted that a image which is not corrupted by noise has very well separated edges and is locally and smoothly varying.

In [14] it is shown that noisy pixel is generally located close to 0 or 255 .

\subsubsection{Fuzzy Impulse Detection Technique}

The paper presents a new impulse noise removal algorithm based on fuzzy impulse detection technique to restore digital images corrupted by impulse noise.

The proposed algorithm performs significantly better than many existing algorithms.

The low complexity makes it very suitable for hardware implementation.

Therefore, it can be used to remove impulse noise in many consumer electronics products such as digital cameras and digital television for its performance and simplicity. 


\section{Algorithm:}

\section{Fuzzy impulse detection}

Input to the algorithm: An image with $20 \%$ noise added

Output: Noise free image.

Step 1: Read the Noisy Image.

Step 2: Create a $3 \times 3$ window, $\mathrm{W}_{\mathrm{ij}}$ centered at $\mathrm{x}_{\mathrm{ij}}$

Step 3: Test to see if $\mathrm{x}_{\mathrm{ij}}$ is a noisy pixel by matching if its intensity is equal to 0 or 255 .

Step 4: If it does not match, then $\mathrm{x}_{\mathrm{ij}}$ is a noise free pixel. Otherwise, calculate maximum value.

$\mathrm{M}_{\mathrm{ij}}$ of $\left|\mathrm{x}_{\mathrm{ij}-} \mathrm{s}_{\mathrm{ij}}\right|$ for all $\mathrm{s}_{\mathrm{ij}}$ is an element which belongs to $\mathrm{W}_{\mathrm{ij}}$ and $\mathrm{s}_{\mathrm{ij}} \neq \mathrm{X}_{\mathrm{ij}}$.

Step 5: Now membership function, $\mathrm{f}_{\mathrm{ij}}$ is evaluated based on $\mathrm{M}$

$$
\mathrm{Fij}=\left\{\begin{array}{cc}
0 & \mathrm{Mij} \leq \mathrm{T} 1 \\
\frac{\mathrm{M} \mathrm{i}, \mathrm{j}-\mathrm{T} 1}{T 2-T 1} & \mathrm{~T} 1 \leq \mathrm{Mij} \leq \mathrm{T} 2 \\
1 & \mathrm{Mij} \geq \mathrm{T} 2
\end{array}\right.
$$

To give the pixel $\mathrm{x} i j$ a fuzzy flag indicating how much it looks like an impulse pixel, the two parameter membership function is used where $\mathrm{T} 1$ and $\mathrm{T} 2$ are two pre-determined parameters. [24]

\subsubsection{Impulse Noise Cancellation}

Step 6: In this step, new value of pixel $\mathrm{x}_{\mathrm{ij}}$ is replaced by a linear combination of its original value $\mathrm{x}_{\mathrm{ij}}$ and the median $\mathrm{m}$ ij of $W_{\text {ij. }}$.

$\mathrm{y}_{\mathrm{ij}}=\left(1-\mathrm{f}_{\mathrm{ij}}\right) * \mathrm{x}_{\mathrm{ij}}+\mathrm{f}_{\mathrm{ij}} * \mathrm{~m}_{\mathrm{ij}}$

where $y_{i j}$ is the restored value of $x_{i j}$.

\subsubsection{Implementation Detail}

The proposed impulse noise removal algorithm based on fuzzy impulse detection technique is used to correct the noisy image and its result is compared with image corrected by median filter.

\subsubsection{Regarding algorithm}

The algorithm suits to find defects in images in which defected area is constantly of darker region than its surroundings. The defected area of lighter region is not properly detected. Also the algorithm is not able to detect defects in mesh like or noisy patterns.

\subsection{Removing Impulse Noise}

Once the pixels corrupted by impulse noise are detected, the next step is the removal of impulse noise. Let say impulse noise is detected at pixel position $\mathrm{x} i j$. The goal is to restore the original pixel value at the pixel position i.e. the pixel value prior to the addition of impulse noise. The aim is to restore the noise free pixel and hence get noise free images. So once the membership function $\mathrm{f} i j$ is calculated for each pixel $\mathrm{x} i j$ of the input image, the following conclusion is drawn.

\begin{tabular}{|c|c|c|}
\hline Fij & $\mathbf{y} \mathbf{i} \mathbf{j}$ & Interpretation \\
\hline 0 & $\mathrm{y} \mathrm{i} \mathrm{j}=\mathrm{xij}$ & $\begin{array}{c}\text { No noise detected } \\
\text { at pixel } \\
\mathrm{x} \text { i j }\end{array}$ \\
\hline 1 & $\mathrm{y} i j=\mathrm{m} i j$ & $\begin{array}{c}\mathrm{x} i j \text { highly } \\
\text { corrupted by }\end{array}$ \\
\hline
\end{tabular}

\begin{tabular}{|c|c|c|}
\hline & & impulse noise. \\
\hline $0<\mathrm{f} \mathrm{i} \mathrm{j<1}$ & $\begin{array}{c}\text { yi } j=\text { linear } \\
\text { combination of } \\
\mathrm{x} \mathrm{i} \mathrm{j} \text { and } \mathrm{m} \mathrm{i} \mathrm{j}\end{array}$ & $\begin{array}{c}\text { Pixel value } \\
\text { corrupted by } \\
\text { impulse noise. }\end{array}$ \\
\hline
\end{tabular}

Where y $i j=$ restored pixel value after noise removal

M $i j=$ median value

\section{EXPERIMENTAL RESULTS}

The results shown are modified version of the original algorithm. In step 4 of the original algorithm, there was a need to calculate the "MINIMUM" value. If this is followed, impulse noise is not removed from the resultant image. Instead, if "MAXIMUM" value is used, the resultant image is free of impulse noise. Test images used are gray scale test images. This algorithm works in iteration for better results. Restored image is better in quality as compared to image after the noise removal by median filter approach [fig C and D]. PSNR value is peak signal to noise ratio which helps to assess the results [1]-[14].

PSNR value is a parameter to assess the resemblance between original image and restored image. Higher is the PSNR Value, greater is the resemblance between original image and restored image i.e. maximum noise is removed.

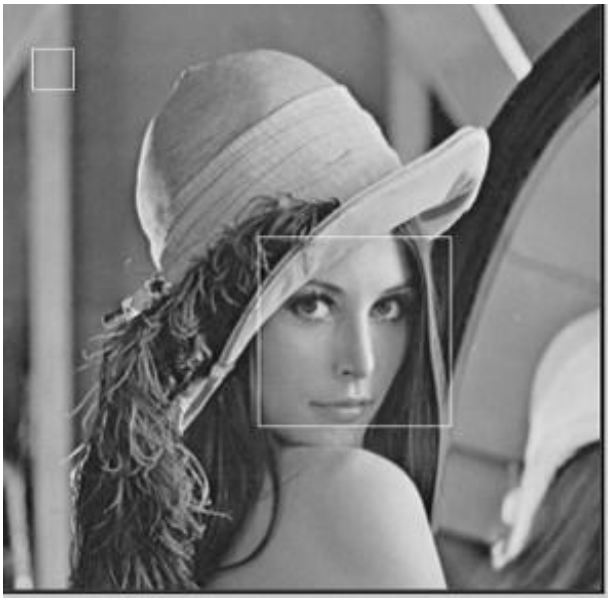

Fig.4 Original and noise free image

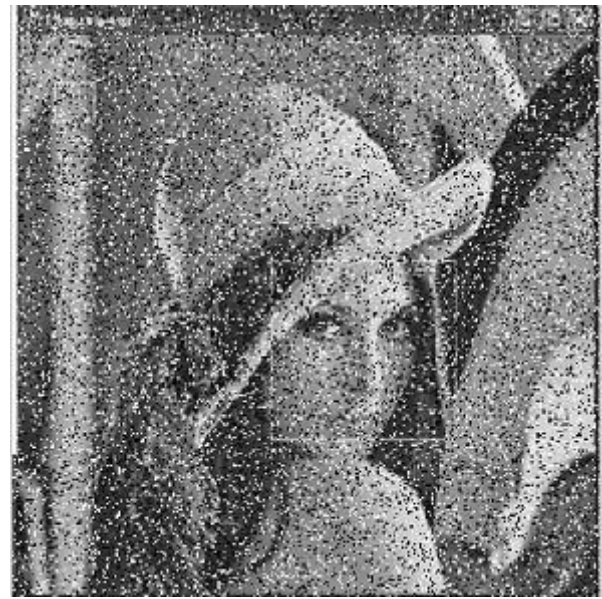

Fig.5 Image with $20 \%$ impulse noise added 


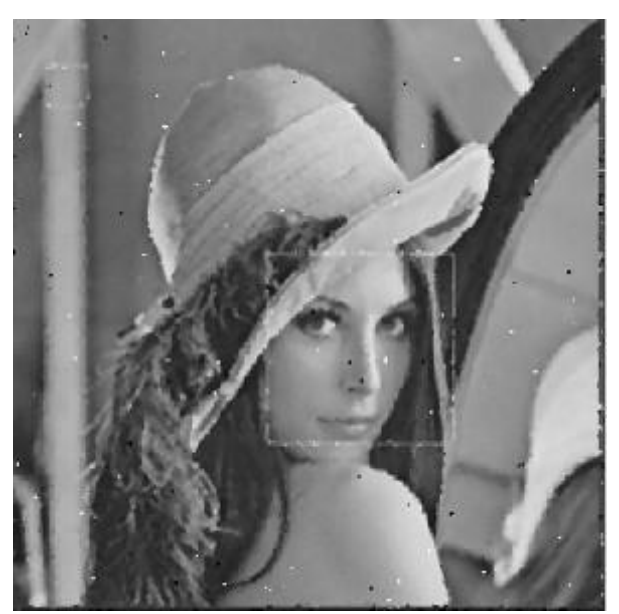

Fig.6 Median filtered image

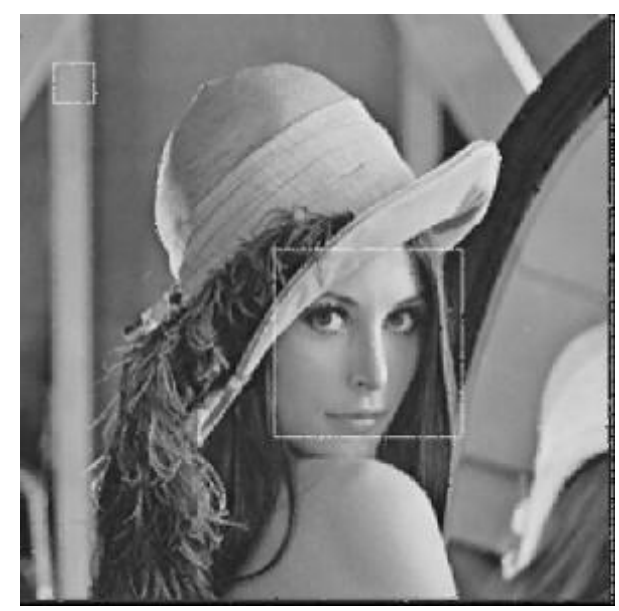

Fig.7 Restored Image after the removal of impulse noise

\section{CONCLUSION}

A new technique to remove impulse noise is presented here. Higher PSNR value indicates that the restored image is of higher quality and nearly similar to the original image. If there is no noise in the image i.e. if the image is noise free then the PSNR value is infinity.

Table 4. Interpretation based on psnr value

\begin{tabular}{|c|c|}
\hline PSNR Value & Interpretation \\
\hline Higher PSNR value & $\begin{array}{c}\text { Restored image is similar to } \\
\text { original image }\end{array}$ \\
\hline Infinity value of PSNR & Noise free image \\
\hline Low PSNR value & $\begin{array}{c}\text { Restored image has greater } \\
\text { amount of }\end{array}$ \\
\hline
\end{tabular}

Higher PSNR value represents better image quality. Therefore, from the results we can see that the proposed noise removal algorithm based on fuzzy impulse detection technique is better than a simple median filter.The algorithm works successfully for binary images as well. The future scope of the noise removal technique is to attain the higher PSNR value so that the restored image is similar to the original image to a large extent i.e. noise free restored image. PSNR value of proposed fuzzy logic based filtered image is 41.7063 whereas for median filtered approach the PSNR value is 36.057. The comparison between PSNR value of the median filtered approach and fuzzy logic based filtered approach depicts that the fuzzy logic based approach outperforms the median filtered approach. The future scope is to improve the PSNR value of the algorithm in order to improve the restored image quality.

Table 5.Comparison between median filter approach and the proposed approach.

\begin{tabular}{|c|c|}
\hline Filtering Approach & PSNR Value \\
\hline Median filter approach & 36.057 \\
\hline Fuzzy logic based approach & 41.706 \\
\hline
\end{tabular}

\section{REFERENCES}

[1] D. Florencio and R.W. Schafer, "Decision-based median filter using local signal statistics," Proc. SPIE, vol. 2308, pp. 268-275, Sept. 1994.

[2] F. Russo and G. Ramponi, "A fuzzy filter for images corrupted by impulse noise," IEEE Signal Process. Lett., vol. 3, no. 6, pp. 168-170, 1996.

[3] T. Chen and K. Ma and L. Chen, "Tri-state median filter for image denoising," IEEE Trans. Image Process., vol. 8, no. 12, pp. 1834-1838,1999.

[4] E. Abreu and M. Lightstone and S. K. Mitra and K. Arakawa, "A new efficient approach for the removal of impulse noise from highly corrupted images," IEEE Trans. Image Process., vol. 5, no. 6, pp. 1012-1025, 1996.

[5] R.C. Hardie and K.E. Barner, "Rank conditioned rank selection filters for signal restoration," IEEE Trans. Image Process., vol. 3, no. 2, pp.192-206, 1994.

[6] G. R. Arce and M. P. McLoughlin, "Theoretical analysis of the MAX/Median filter," IEEE Trans. Acoust., Speech, Signal Processing, vol. ASSP-35, pp. 60-69, Jan. 1987.

[7] M. Gabbouj, E. J. Coyle, J. Neal, and C. Gallagher, "An overview of median and stack filtering," Circuits Syst. Signal Process., vol. 11, pp.7-45, 1992.

[8] Y. H. Lee and S. Tantaratana, "Decision-based order statistics filters,"IEEE Trans. Acoust., Speech, Signal Processing, vol. 38, pp. 406-420,Mar. 1990.

[9] Azadeh Noori Hoshyar and Adel Al-Jumaily and Afsaneh Noori Hoshyar, "Comparing the Performance of Various Filters on Skin Cancer Images," Procedia Computer Science 42 ( 2014 ) 32 - 37.

[10] Gajanand G, “Algorithm for Image Processing Using Improved Median Filter and Comparison of Mean, Median and Improved Median Filter",International Journal of Soft Computing and Engineering (IJSCE) ISSN: 2231-2307, Volume-1, Issue-5, November 2011.

[11] Alain H, Djemel Z," Image quality metrics: PSNR vs. SSIM", International Conference on Pattern Recognition, 2010.

[12] H. L. Eng and K. Ma, "Noise adaptive soft-switching median filter," IEEE Trans. Image Process., vol. 10, no. 2, pp. 242-251, 2001. 
[13] T. Sun and Y. Neuvo, "Detail-preserving median based filters in image processing," Pattern Recognit. Lett., vol. 15, pp. 341-347, Apr. 1994.

[14] J. Astola and P. Kuosmanen, "Fundamentals of Nonlinear Digital Filtering", Boca Raton, Florida: CRC Press, 1997.

[15] Pitas I, Venetsanopoulos A,"Nonlinear mean filters in image processing", IEEE Transactions on Acoustics, Speech and Signal Processing, Volume:34, Issue: 3, 573 - 584, Jun 1986.

[16] Pei YH; Shin SC; Feng CH, "Generic 2D Gaussian smoothing filter for noisy image processing", IEEE Region 10 Conference ( TENCON), 2007.

[17] Pawan P, Manoj G, Sumit S, Ashok KN," Image Denoising by Various Filters for Different Noise", International Journal of Computer Applications (0975 8887), Volume 9- No.4, November 2010.

[18] Sarita D, "De-noising Techniques - A Comparison", B.E., Andhra University College of Engineering, Visakhapatnam, India, 2000.

[19] C.-T. Chen and L.-G. Chen, "A self-adjusting weighted median filter for removing impulse noise in image," in
Proc. IEEE Int. Conf. on Image Processing, 1998, pp. 419-422.

[20] D. A. F. Florencio and R. W. Schafer, "Decision-based median filter using local signal statistics," Proc. SPIE, vol. 2308, pp. 268-275, 1994.

[21] T. Kasparis, N. S. Tzannes, and Q. Chen, "Detailpreserving adaptive conditional median filters," J. Electron. Imag., vol. 1, no. 14, pp. 358-364, 1992.

[22] A. Sawant, H. Zeman, D. Muratore, S. Samant, and F. DiBianka, "An adaptive median filter algorithm to remove impulse noise in X-ray and CT images and speckle in ultrasound images," Proc. SPIE, vol. 3661, pp. 1263-1274, Feb. 1999.

[23] Gouchol Pok, Jyh-Charn Liu, and Attoor Sanju Nair, "Selective Removal of Impulse Noise Based on Homogeneity Level Information," IEEE Transactions on Image Processing, vol. 12, no. 1, January 2003.

[24] W. Luo, "Efficient Removal of Impulse Noise from Digital Images," IEEE Transactions on Consumer 524 Electronics, Vol. 52, No. 2, MAY 2006. 